\title{
Gender affirmative care of transgender people: a single center's experience in Korea
}

\author{
Hyun Hye Lim, Yun Ha Jang, Gyu Yeon Choi, Jeong Jae Lee, Eun Sil Lee \\ Department of Obstetrics and Gynecology, Soonchunhyang University Seoul Hospital, Soonchunhyang University, College of Medicine, Seoul, Korea
}

\section{Objective}

To investigate the clinical characteristics and medical management of transgender people in South Korea.

\section{Methods}

The electronic medical records of 54 transgender persons who had visited Soonchunhyang University Hospital from January 2016 to December 2017 for medical care were retrospectively reviewed. We identified patient demographics and gender identity-related characteristics. Moreover, we compared our hospital protocol with official guidelines.

\section{Results}

At the time of the medical record search, the average age of these 52 transgender persons was 27 years, and 46 $(88.5 \%)$ were Korean. Ten (19.2\%) persons had a mental disorder other than gender dysphoria. Gonadotropinreleasing hormone agonist, estrogen, antiandrogen agents, and testosterone were used according to the guidelines issued by the World Professional Association for Transgender Health and the Endocrine Society. Ten (19.2\%) transgender persons, including 6 (22.2\%) male-to-females (MTFs) and 4 (16.0\%) female-to-males (FTMs), had a mental disorder other than gender dysphoria. Among persons who were administered testosterone, 3 had high triglyceride and lipoprotein cholesterol levels. Nine patients, including 6 (66.7\%) MTFs and 3 (33.3\%) FTMs, underwent both gonadectomy and gender affirmative surgery. Seven (43.8\%) persons, including 1 (14.3\%) MTF and 6 (85.7\%) FTMs, underwent only gonadectomy. There was a significant difference $(P=0.040)$ between MTFs and FTMs.

\section{Conclusion}

Medical providers should have adequate knowledge of and experience in managing transgender persons and be familiar with the relevant guidelines and literature. Long-term follow-up examinations should also be performed.

Keywords: Gender dysphoria; Transgender persons; Gender affirmative care

\section{Introduction}

According to the World Professional Association for Transgender Health (WPATH), the term "transgender" is defined as a diverse group of individuals who cross or transcend culturally defined categories of gender. By this definition, the gender identity of transgender people differs in varying degrees from the sex they were assigned at birth [1]. Gender dysphoria refers to distress caused by a discrepancy between a person's gender identity and that person's sex assignment at birth [1]. In contrast, a gender-confirming or cisgender person refers to someone whose gender identity matches the sex assigned at birth [2].

The term "gender identity disorder" in the International Classification of Diseases, 10th Revision was changed to "gender dysphoria" in the Diagnostic and Statistical Manual of Mental Disorders, 5th edition. In the International Classi-

Received: 2018.07.18. Revised: 2018.10.04. Accepted: 2018.10.10. Corresponding author: Eun Sil Lee

Department of Obstetrics and Gynecology, Soonchunhyang University Seoul Hospital, Soonchunhyang University, College of Medicine, 59 Daesagwan-ro, Yongsan-gu, Seoul 04401, Korea E-mail: eslee165@schmc.ac.kr

https://orcid.org/0000-0003-4132-5533

Articles published in Obstet Gynecol Sci are open-access, distributed under the terms of the Creative Commons Attribution Non-Commercial License (http://creativecommons. org/licenses/by-nc/3.0/) which permits unrestricted non-commercial use, distribution, and reproduction in any medium, provided the original work is properly cited.

Copyright $\odot 2019$ Korean Society of Obstetrics and Gynecology 


\section{Obstetrics \& Gynecology Science}

Hyun Hye Lim, et al. Affirmative care of transgender people

fication of Diseases, 11th Revision, this was further changed to "gender incongruence" [3]. The term gender identity disorder has not been used recently.

There have been no accurate estimates with respect to the size of the transgender population. Some transgender people live with their gender dysphoria without transition. Some choose social transition without medical or surgical transition. Others obtain hormones from non-medical providers including those on the internet, whereas some undergo sex affirmation surgery without hormonal therapy (HT). A very diverse living pattern makes it difficult for researchers to decide whom to count for transgender prevalence. In the Netherlands, the 1:11,900 prevalence of male-tofemale (MTF) and 1:30,100 prevalence of female-to-male (FTM) transsexualism was reported at the end of 1990. This result was derived from patients diagnosed as transsexual by mental health professionals [4]. The prevalence of transsexualism in Singapore was estimated to be $1 / 2,900$ for male transsexualism and 1/8,300 for female transsexualism [5]. However, such numbers grossly underestimate the existence of transgender people who cannot or do not access medical services. More direct methods by questioning gender identity in the general population have shown that the prevalence of transgender ranges from $0.5 \%$ to $1.2 \%$ [6-11].

Older adolescents and adults may seek cross-sex hormones, surgery, or a range of medical services. Such health care is popularly known as sex or gender reassignment or as gender confirming or gender affirming health care. Young adolescents going through puberty may seek gender-affirming health care involving gonadotropin-releasing hormone (GnRH) agonist. [2]

Reports on the characteristics of the medical management of transgender people, such as health care and cross-sex HT, are rare in South Korea. Lee et al. [12] have reported barriers in gender affirming health care among transgender patients, including medical costs, medical providers' biased and discriminatory attitudes and lack of knowledge, and the lack of medical care providers and facilities for transgender people.

The purpose of this study was to provide information on the clinical characteristics and medical management of transgender people at a single university gender clinic in South Korea.

\section{Materials and methods}

Electronic medical records of 55 transgender patients who had visited the obstetrics and gynecology department at Soonchunhyang University Hospital in Seoul at least once between January 2016 and December 2017 were reviewed. These patients were diagnosed with gender identity disorder before or after the first visit to the aforementioned department. Among these 55 patients, 25 were trans-male (assigned sex was female but gender identity was male), whereas 27 of them were trans-female (assigned sex was male but gender identity was female). Two patients whose assigned gender was male had a non-binary gender identity, meaning that they did not identify themselves as either male or female. This study excluded 1 hypogonadism patient whose assigned gender was ambiguous. A total of 54 patients were reviewed.

We used the term "gender dysphoria" rather than "gender identity disorder," although the term "gender identity disorder" was used in the Korean Standard Classification of Diseases, 10th Revision.

We identified the demographics of these transgender patients, such as age, race/ethnicity, and employment status. We obtained gender identity-related characteristics, such as the time of the first experience of gender dysphoria, initial psychiatric diagnosis, mental health, time of the first visit to a medical care provider, and whether or not they had received gender affirmative services such as HT and past or current surgery. Moreover, we compared our hospital protocol with official guidelines, including the WPATH guideline, Endocrine Society Clinical Guideline, and the University of California, San Francisco (UCSF) guideline.

Finally, we evaluated differences in each of these items between the FTM and MTF groups.

The univariate descriptive statistics were presented as mean, median, standard deviation (SD), frequency, and ratio of several items. In addition to the descriptive statistics, we conducted a bivariate analysis of gender identity to assess the differences between the FTM and MTF groups.

\section{Results}

\section{Demographics}

The demographic characteristics of the transgender patients 


\title{
Obstetrics \& Gynecology Science
}

\author{
Vol. 62, No. 1, 2019
}

are shown in Table 1. At the time of medical record search, the average age of the 52 transgender patients was 27 years ( $\mathrm{SD}=9.0$ years). Forty-six (88.5\%) transgender patients were Korean, 5 (9.6\%) were Caucasian, and 1 (1.9\%) was of African-American ethnicity. The 2 non-binary transgender patients were Koreans.

\section{Gender identity-related characteristics}

Table 2 presents the gender identity-related characteristics of the transgender patients. Fourteen (26.9\%), 7 (13.5\%), and $4(7.7 \%)$ patients first experienced gender dysphoria in their elementary, middle, and high school years, respectively. Thus, a total of 25 (48.1\%) patients first experienced gender dysphoria during the school years. Six (11.5\%) patients first experienced gender dysphoria when they were in preschool. Only $1(1.9 \%)$ experienced gender dysphoria after reaching adulthood. The 2 non-binary gender patients first experienced gender dysphoria during high school and in adulthood, respectively.

Thirty-four transgender patients and 2 non-binary patients were diagnosed with gender identity disorder by psychiatrists of other hospitals. Seventeen patients were diagnosed by our institution's psychiatrists, and 1 had no record of psychiatric diagnosis.

Seven $(13.5 \%)$ patients first visited a medical care provider during their adolescence. Thirty-five (67.3\%) transgender patients and 2 patients with non-binary gender identity had visited a medical care provider when they were adults, which was the most common.

\section{Mental health}

Ten (19.2\%) transgender patients, including 6 (22.2\%) MTFs and $4(16.0 \%)$ FTMs, had a mental disorder other than gender dysphoria, showing a significant difference $(P=0.019)$ in the number of mental disorders between the 2 groups. Of these 10 patients with mental disorders and 2 with nonbinary gender identity diagnosed with major depressive disorder (MDD), 2 had anxiety disorder and 2 had other mental disorders (Fig. 1). Among the 10 transgender patients with mental disorders, 2 had suicidal ideation.

\section{Gender affirmative hormone therapy}

1) Guideline for adolescents

In this study, there were 2 FTM patients (age at the time of first visit: 15 and 16 years) who visited our clinic in their

Table 1. Demographics of subjects enrolled in this study

\begin{tabular}{|c|c|c|c|c|}
\hline Variable & Total $(n=52)$ & $\operatorname{MTF}(n=27)$ & FTM $(n=25)$ & $P$-value \\
\hline Age in year ${ }^{a)}$ & & & & 0.168 \\
\hline $\begin{array}{l}\text { Mean (SD) } \\
\text { Median } \\
\text { Range }\end{array}$ & $\begin{array}{r}27.0(9.0) \\
24.0 \\
15-55\end{array}$ & $\begin{array}{c}28.1(9.3) \\
25 \\
19-55\end{array}$ & $\begin{array}{c}24.5(6.8) \\
23 \\
15-43\end{array}$ & \\
\hline Population age strata in sample (yr) & & & & 0.215 \\
\hline $\begin{array}{l}10-17 \\
18-25 \\
26-49 \\
\geq 50\end{array}$ & $\begin{array}{c}3(5.8) \\
29(55.8) \\
18(34.6) \\
2(3.8)\end{array}$ & $\begin{array}{c}0(0) \\
15(55.6) \\
10(37.0) \\
2(7.4)\end{array}$ & $\begin{array}{l}3(12.0) \\
14(56.0) \\
8(32.0) \\
0(0)\end{array}$ & \\
\hline Race/ethnicity & & & & 0.395 \\
\hline $\begin{array}{l}\text { Korean } \\
\text { Caucasian } \\
\text { African American }\end{array}$ & $\begin{array}{c}46(88.5) \\
5(9.6) \\
1(1.9)\end{array}$ & $\begin{array}{c}25(92.6) \\
2(7.4) \\
0(0.0)\end{array}$ & $\begin{aligned} 21 & (84.0) \\
3 & (12.0) \\
1 & (4.0)\end{aligned}$ & \\
\hline Employment & & & & 1.000 \\
\hline $\begin{array}{l}\text { Working } \\
\text { Not working } \\
\text { Student } \\
\text { Not indicated }\end{array}$ & $\begin{aligned} 19 & (36.5) \\
5 & (9.6) \\
16 & (30.8) \\
12 & (23.1)\end{aligned}$ & $\begin{array}{r}10(37.0) \\
3(11.1) \\
8(29.6) \\
6(22.2)\end{array}$ & $\begin{array}{l}9(36.0) \\
2(8.0) \\
8(32.0) \\
6(24.0)\end{array}$ & \\
\hline
\end{tabular}

Values are presented as number (\%).

MTF, male-to-female; FTM, female-to-male; SD, standard deviation.

${ }^{\text {a) }}$ At the time of medical record search. 


\section{Obstetrics \& Gynecology Science}

Hyun Hye Lim, et al. Affirmative care of transgender people

Table 2. Gender identity related characteristics

\begin{tabular}{|c|c|c|c|c|}
\hline Variable & Total $(n=52)$ & MTF $(n=27)$ & FTM $(n=25)$ & $P$-value \\
\hline Time of the first experienced gender dysphoria & & & & 0.090 \\
\hline $\begin{array}{l}\text { Preschooler } \\
\text { Students } \\
\text { Adult } \\
\text { Not indicated }\end{array}$ & $\begin{array}{c}6(11.5) \\
25(48.1) \\
1(1.9) \\
20(38.5)\end{array}$ & $\begin{array}{c}1(3.7) \\
16(59.3) \\
1(3.7) \\
9(33.3)\end{array}$ & $\begin{array}{c}5(20.0) \\
9(36.0) \\
0(0) \\
11(44.0)\end{array}$ & \\
\hline Initial diagnosis at the mental health professionals & & & & 0.005 \\
\hline $\begin{array}{l}\text { Other hospitals } \\
\text { Our hospital } \\
\text { Not indicated }\end{array}$ & $\begin{array}{c}34(65.4) \\
17(32.7) \\
1(1.9)\end{array}$ & $\begin{array}{c}23(85.2) \\
4(14.8) \\
0(0.0)\end{array}$ & $\begin{array}{c}11(44.0) \\
13(52.0) \\
1(4.0)\end{array}$ & \\
\hline Mental health & & & & 0.019 \\
\hline $\begin{array}{l}\text { Any assessed psychiatric diagnoses } \\
\text { No assessed psychiatric diagnoses } \\
\text { Not indicated }\end{array}$ & $\begin{array}{l}10(19.2) \\
23(44.2) \\
19(36.5)\end{array}$ & $\begin{array}{r}6(22.2) \\
16(59.3) \\
5(18.5)\end{array}$ & $\begin{array}{r}4(16.0) \\
7(28.0) \\
14(56.0)\end{array}$ & \\
\hline Time of the first visiting medical center & & & & 0.214 \\
\hline $\begin{array}{l}\text { Adolescent } \\
\text { Adult } \\
\text { Not indicated }\end{array}$ & $\begin{array}{r}7(13.5) \\
35(67.3) \\
10(19.2)\end{array}$ & $\begin{array}{r}3(11.1) \\
21(77.8) \\
3(11.1)\end{array}$ & $\begin{array}{r}4(16.0) \\
14(56.0) \\
7(28.0)\end{array}$ & \\
\hline Age of $\mathrm{HT}$ initiation & & & & 0.135 \\
\hline $\begin{array}{l}\text { Mean (SD) } \\
\text { Median } \\
\text { Range }\end{array}$ & $\begin{array}{c}23.6(7.9) \\
22.0 \\
12-52\end{array}$ & $\begin{array}{c}21.3(4.6) \\
21.0 \\
12-32\end{array}$ & $\begin{array}{c}26.4(10.3) \\
24.0 \\
13-52\end{array}$ & \\
\hline Period of hormone use (/months) & & & & 0.742 \\
\hline $\begin{array}{l}\text { Mean (SD) } \\
\text { Median } \\
\text { Range }\end{array}$ & $\begin{array}{c}36.9(34.6) \\
36 \\
1-204\end{array}$ & $\begin{array}{c}42.8(43.4) \\
36 \\
1-204\end{array}$ & $\begin{array}{c}31.7(20.4) \\
36 \\
1-66\end{array}$ & \\
\hline \multicolumn{5}{|l|}{ Any gender affirmative surgery } \\
\hline $\begin{array}{l}\text { Lower body surgery } \\
\text { Breast surgeryc }\end{array}$ & $\begin{array}{l}23(42.2) \\
21(40.4)\end{array}$ & $\begin{array}{r}13(48.1) \\
6(22.2)\end{array}$ & $\begin{array}{l}10(40.0) \\
15(60.0)\end{array}$ & $\begin{array}{l}0.588 \\
0.010\end{array}$ \\
\hline
\end{tabular}

Values are presented as number (\%).

MTF, male-to-female; FTM, female-to-male; HT, hormonal therapy; SD, standard deviation.

${ }^{a}$ In elementary, middle, and high school; b) Underwent surgery or plan to surgery. 1) Genital plastic surgery: FTM - vuvlovaginoplasty, MTF - metoidioplasty or phalloplasty. 2) Gonadectomy: FTM - hysterecotmyand both salpingo-oophorectomy, MTF - penectomy, orchiectomy; c) Underwent surgery or plan to surgery: mastectomy or breast augmentation surgery.

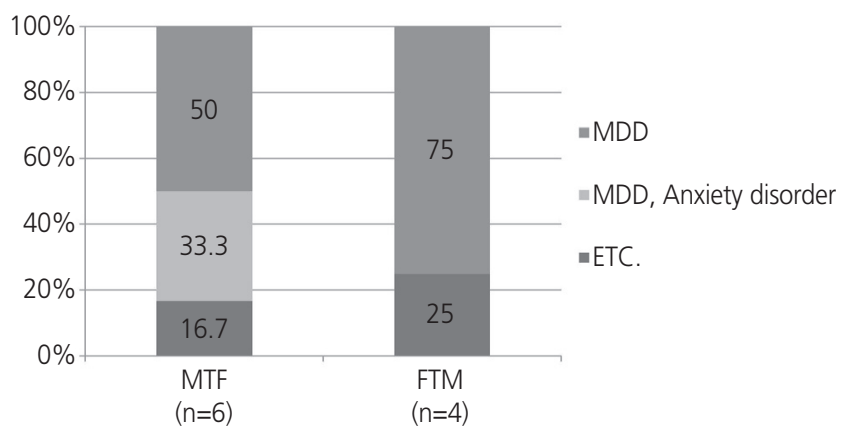

Fig. 1. Mental health status of male-to-female and female-tomale transgender people. MTF, male-to-female; FTM, female-tomale; MDD, major depressive disorder. adolescence and underwent physical interventions. Physical intervention was performed in accordance with the WPATH/ Endocrine Society Clinical Guideline for adolescents. Prior to the initiation of $\mathrm{GnRH}$ agonist, we confirmed the criteria for the adolescents, referred them to mental health professionals, and measured their baseline laboratory values, including bone mineral density (BMD). Height, weight, blood pressure (BP), and tanner stage were monitored every 3 to 6 months, and serum hormones, such as estrogen and testosterone, were measured every 6 to 12 months. BMD was measured again approximately 2 years after the initiation of $\mathrm{HT}$.

We used a GnRH agonist during the initial intervention, 


\title{
Obstetrics \& Gynecology Science
}

\author{
Vol. 62, No. 1, 2019
}

and then administered cross-sex hormone therapy if the patient was older than 15 years and experienced persisting gender dysphoria. We administered cross-sex HT after obtaining consent from both patients and parents, and after informing them of its side effects, risks, and irreversibility in some respects. Patients were referred to psychiatrists to obtain a medical certificate. One patient received irreversible intervention - top surgery - after more than 12 months of testosterone treatment, as outlined in the official guidelines. This series of treatments was performed along with psychiatric care and counseling.

\section{2) Guideline for adults}

We compared the procedures for HT in the WPATH/Endocrine Society Clinical Guideline with our protocol. Most of the procedures in our protocol were the same as those of the guidelines. HT was initiated after the gender dysphoria diagnosis by mental health professionals. Before HT was performed, patients received detailed explanations of the side effects, risks, and irreversible physical changes, and consent was obtained. We also performed history taking, physical examination, and appropriate baseline laboratory tests. We measured the laboratory test twice in the first year and then 1 to 2 times per year. However, we have not collaborated with the general surgery or any other department. Sex reassignment surgeries (SRSs) for transgender people were not performed owing to the absence of skilled and experienced surgeons and multidisciplinary specialty teams in our institution.

3) Form and dosage of hormonal therapy A comparison of the type and dosage of HT between the Endocrine Society Clinical Practice Guideline/UCSF guideline and our protocol is summarized in Table 3.

Table 3. Comparison of form and dosage of hormones used

\begin{tabular}{|c|c|c|}
\hline \multirow{2}{*}{ Form and type } & \multicolumn{2}{|c|}{ Dosage } \\
\hline & Official guidelines ${ }^{a)}$ & Our protocol \\
\hline \multicolumn{3}{|l|}{ MTF hormone regimen } \\
\hline \multicolumn{3}{|l|}{ Estrogen } \\
\hline Oral estradiol (Progynova) & 2-6 mg/d (oral or sublingual) & $2-6 \mathrm{mg} / \mathrm{d}$ (oral or sublingual) \\
\hline Estradiol transdermal patch (new patch placed every $3-5$ days) & $0.025-0.2 \mathrm{mg} / \mathrm{d}$ & Not used \\
\hline Transdermal estrogen gel (Estreva gel $0.1 \%$ ) & Gel or cream can be used & 1.5-3.0 mg daily \\
\hline Parenteral estradiol valerate & $5-30 \mathrm{mg} \mathrm{IM} / 2 \mathrm{wk}$ & $5-20 \mathrm{mg} \mathrm{IM} / 2 \mathrm{wk}$ \\
\hline Parenteral estradiol cypionate & 2-10 mg weekly & Not used \\
\hline \multicolumn{3}{|l|}{ Antiandrogen } \\
\hline Spironolactone (Aldactone) & $100-300 \mathrm{mg} / \mathrm{d}$ & 50-200 mg/d (oral) \\
\hline Cyproterone acetate (Androcur) & $25-50 \mathrm{mg} / \mathrm{d}$ & 50-100 mg daily (oral) \\
\hline GnRH agonist (Leuprorelin) & $\begin{array}{l}3.75 \text { mg SC monthly } \\
11.25 \text { mg SC 3-monthly }\end{array}$ & 11.25 mg SC 3-monthly \\
\hline \multicolumn{3}{|l|}{ FTM hormone regimen } \\
\hline \multicolumn{3}{|l|}{ Parenteral } \\
\hline Testosterone enanthate (Jenasterone) & $\begin{array}{c}\text { 100-200 mg SC (IM) every } 2 \text { wk or } \\
\text { SC 50\% per week }\end{array}$ & $\begin{array}{l}30-50 \mathrm{mg} \text { weekly SC or } \\
50-250 \mathrm{mg} \mathrm{IM} / 2 \text { wk }\end{array}$ \\
\hline Testosterone undecanoate (Nevido) & 1,000 mg every 12 wk & 1,000 mg every $12-16$ wk \\
\hline \multicolumn{3}{|l|}{ Transdermal } \\
\hline Testosterone gel 2\% (Tostrex gel 2\%) & $30-120 \mathrm{mg} / \mathrm{d}$ & $10-60 \mathrm{mg} / \mathrm{d}$ \\
\hline Testosterone gel 1.6\% GnRH agonist (Leuprorelin) & $\begin{array}{l}3.75 \text { mg SC monthly } \\
11.25 \text { mg SC 3-monthly }\end{array}$ & 11.25 mg SC 3-monthly \\
\hline
\end{tabular}




\section{Obstetrics \& Gynecology Science}

Hyun Hye Lim, et al. Affirmative care of transgender people

Estrogen and antiandrogen were administered to the MTFs. We prescribed 2-6 mg estrogen per day taken sublingually or orally and 1.5-3 mg transdermal estrogen gel daily either in combination with oral estrogen or alone. When we prescribed estradiol, we preferred sublingual estradiol valerate instead of the oral form for feminizing HT since prior researchers have reported the effectiveness of sublingual administration in maintaining high blood estradiol concentration and low E1/E2 ratio [13]. Parenteral estrogen valerate of 5-20 mg was administered via intramuscular (IM) injection every 2 weeks. An antiandrogen agent was used for MTF patients who had not undergone gonadectomy. We prescribed antiandrogen agents, such as oral spironolactone (50-200 $\mathrm{mg}$ daily) or oral cyproterone acetate (50-100 mg daily), in combination with an estrogen agent. For estrogen gels and creams, prescriptions were available in the UCSF guideline, but the details of dosage and usage were not provided. We prescribed estrogen gels; these were rarely used alone, and were used in very small quantities in combination with oral or sublingual estrogen.

We provided parenteral and transdermal administration of testosterone for FTMs, depending on their usage. Testosterone enanthate and testosterone undecanoate were administered parenterally. Testosterone enanthate $30-50 \mathrm{mg}$ via subcutaneous injection or the same hormone of $50-250 \mathrm{mg}$ via IM injection was administered to the patients weekly or every 2 weeks, respectively. Testosterone undecanoate 1,000 mg with 12-16-week intervals was also prescribed.

We administered GnRH agonist for adolescent FTMs or MTFs to inhibit puberty-induced changes and reduce gender dysphoria before cross-sex HT. However, we discontinued the use of GnRH agonist when testosterone therapy was initiated for FTMs. We also administered GnRH agonist to stop menstruation prior to testosterone treatment for FTMs, to suppress testosterone level, and to inhibit morning erection for MTFs prior to gonadectomy.

\section{4) Follow-up examination}

The FTM patients were evaluated every 3 months to monitor appropriate signs of virilization and the development of adverse reactions. During the first year, we measured serum testosterone and estradiol every 3 months until levels were in the normal physiologic male range (testosterone: 400-700 $\mathrm{ng} / \mathrm{dL}$, estradiol: $<50 \mathrm{pg} / \mathrm{mL}$ ). Moreover, we measured their hemoglobin levels and monitored their weight, BP, and lipids at regular intervals.

We evaluated MTF patients every 3 months to monitor appropriate signs of feminization and the development of adverse reactions. During the first year, we measured their serum testosterone $(<50 \mathrm{ng} / \mathrm{dL}$ ) and estradiol (peak physiologic range: $100-200 \mathrm{pg} / \mathrm{mL}$ ) levels every 3 months. For MTF patients on spironolactone, monitoring of serum electrolytes (primarily potassium) was performed every 3 months during the first year and annually thereafter.

In the most recent laboratory tests, testosterone, estrogen, prolactin, hemoglobin, electrolyte and lipid panel values were analyzed. Estrogen, prolactin, hemoglobin, and electrolytes, especially potassium, were all in the normal range. One patient had a high testosterone level, and 3 patients had low testosterone levels in the FTM group. In these cases, the patient's symptoms were evaluated, and we accordingly adjusted the dosage of testosterone.

Five patients in the MTF group had high testosterone levels. Among these patients, 2 were receiving HT. In 1 patient, spironolactone was discontinued owing to hyperkalemia (5.3 $\mathrm{mmol} / \mathrm{L})$. However, from the last visit, we confirmed that the potassium level became normal; thus, spironolactone was prescribed again. The other patient was administered an increased dose of spironolactone from 50 to $100 \mathrm{mg} /$ day. We adjusted the dosage of antiandrogen by measuring blood testosterone and potassium levels, and also by investigating patients' complaints of changes in urinary frequency or dryness due to spironolactone administration.

Triglyceride (TG) and low-density lipoprotein cholesterol (LDL-C) were mainly increased because of testosterone treatment. The average values of LDL-C were significantly different between the FTM and MTF groups $(123.9 \mathrm{mg} / \mathrm{dL}$ in the FTM group vs. $91.5 \mathrm{mg} / \mathrm{dL}$ in the MTF group; $P=0.007$ ) (Table 4). Among the patients administered testosterone, 3 had high TG and LDL-C levels. One patient did not have followup laboratory data, whereas the other 2 patients' LDL-C and TG levels were measured at the follow-up visit.

Among the 23 patients who underwent a BMD test, 5 were subjected to the test before $H T$, whereas 18 were tested after beginning $\mathrm{HT}$. Z- and T-scores were all within the normal ranges. Two non-binary patients had a BMD test result within the normal range.

\section{Gender affirmative surgery}

We investigated gender affirmative surgery by classifying it 


\title{
Obstetrics \& Gynecology Science
}

\author{
Vol. 62, No. 1, 2019
}

Table 4. Lipid profile test results

\begin{tabular}{|c|c|c|c|c|}
\hline Variable & Total $(n=38)$ & MTF $(n=24)$ & FTM $(n=14)$ & $P$-value \\
\hline Total cholesterol (mg/dL) & & & & 0.244 \\
\hline $\begin{array}{l}\text { Mean (SD) } \\
\text { Median } \\
\text { Range }\end{array}$ & $\begin{array}{c}169.4(32.0) \\
165.5 \\
100-248\end{array}$ & $\begin{array}{c}161.6(27.0) \\
165.5 \\
100-200\end{array}$ & $\begin{array}{c}182.8(36.1) \\
177.0 \\
141-248\end{array}$ & \\
\hline LDL-C (mg/dL) & & & & 0.007 \\
\hline $\begin{array}{l}\text { Mean (SD) } \\
\text { Median } \\
\text { Range }\end{array}$ & $\begin{array}{c}102.3(33.6) \\
102.5 \\
23-176\end{array}$ & $\begin{array}{c}91.5(31.5) \\
93.0 \\
23-176\end{array}$ & $\begin{array}{c}123.9(27.0) \\
118.5 \\
84-174\end{array}$ & \\
\hline $\mathrm{HDL}-\mathrm{C}(\mathrm{mg} / \mathrm{dL})$ & & & & 0.178 \\
\hline $\begin{array}{l}\text { Mean (SD) } \\
\text { Median } \\
\text { Range }\end{array}$ & $\begin{array}{c}62.3(14.5) \\
62.5 \\
23-89\end{array}$ & $\begin{array}{c}64.1(15.6) \\
65.5 \\
23-89\end{array}$ & $\begin{array}{c}59.2(12.4) \\
58.5 \\
38-84\end{array}$ & \\
\hline Triglyceride (mg/dL) & & & & 1.000 \\
\hline $\begin{array}{l}\text { Mean (SD) } \\
\text { Median } \\
\text { Range }\end{array}$ & $\begin{array}{c}97.8(51.6) \\
79.5 \\
35-271\end{array}$ & $\begin{array}{c}95.5(47.6) \\
79.5 \\
40-256\end{array}$ & $\begin{array}{c}101.8(59.4) \\
86.5 \\
35-271\end{array}$ & \\
\hline
\end{tabular}

Reference values: 1) Total cholesterol: normal (less than $200 \mathrm{mg} / \mathrm{dL}) ; 2$ ) LDL cholesterol: optimal (less than 100 mg/dL), near optimal (100-129 $\mathrm{mg} / \mathrm{dL}$ ); 3) HDL cholesterol: normal (above $40 \mathrm{mg} / \mathrm{dL}$ ); 4) Triglyceride: normal (less than $150 \mathrm{mg} / \mathrm{dL}$ ).

MTF, male-to-female; FTM, female-to-male; SD, standard deviation; LDL-C, low-density lipoprotein cholesterol; HDL-C, high-density lipoprotein cholesterol.

into lower body surgery and breast surgery. The lower body surgery was divided into 2 types: gonadectomy only and gonadectomy with genital plastic surgery.

The total number of those who had already undergone lower body surgery or were planning on receiving it was 23 (44.2\%). Between the FTMs and MTFs, there was no significant $(P=0.588)$ difference in the number of patients undergoing lower body surgery (Table 2 ). The number of patients who underwent both gonadectomy and genital plastic surgery was 9: 6 (66.7\%) MTFs and 3 (33.3\%) FTMs. Seven $(43.8 \%)$ patients underwent gonadectomy only, including 1 (14.3\%) MTF and 6 FTMs (85.7\%), showing significant difference $(P=0.040)$ between MTFs and FTMs. The 2 patients with non-binary gender identity neither underwent lower body surgery nor had any plan to do so (Table 2).

In most cases, surgery was performed before the first visit to our hospital. Of the 22 patients who underwent surgery, 15 (68.2\%) had done so before gender affirmative care and $7(31.8 \%)$ underwent surgery during gender affirmative care in our clinic. The ratios for MTFs and FTMs were almost similar (Fig. 2). When patients wanted to undergo SRS, we evaluated them in accordance with the official guidelines. We provided a medical certificate if they met the surgical conditions thereafter.

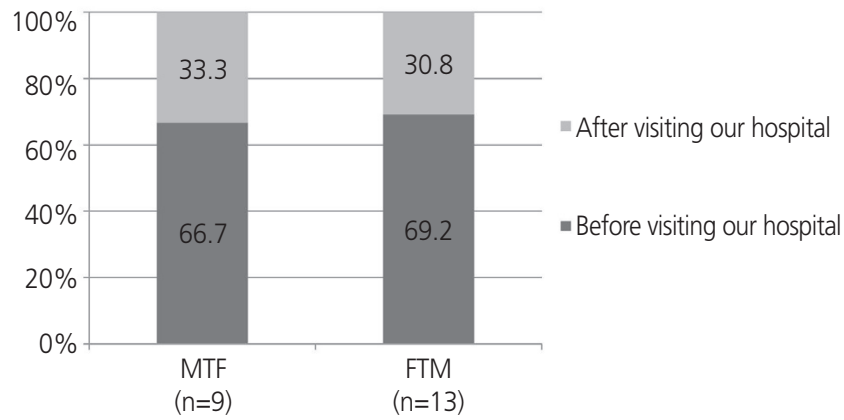

Fig. 2. Timing for gender affirmative surgery. MTF, male-to-female; FTM, female-to-male.

\section{Discussion}

Lee et al. [12] provide the following reasons for why transgender people do not receive the necessary transitional therapies: medical costs, transgender people's negative experiences with medical providers, lack of knowledge of gender transition among medical providers, and lack of information on gender transition provided to transgender people. To overcome these problems, this study was designed to present updated information on gender transition in South Korea.

Transgender people suffer from various mental health problems, which are related to long-term gender dysphoria 


\section{Obstetrics \& Gynecology Science}

Hyun Hye Lim, et al. Affirmative care of transgender people

and/or chronic minority stress [1]. The current study indicated that $19.2 \%$ of transgender people were diagnosed with a mental disorder, mainly MDD and anxiety disorder. This percentage is higher than the one reported in the mental health survey by the Korean Ministry of Health and Welfare in 2016, reporting an MDD prevalence of only 5.0\% [14]. Additionally, 2 patients in the present study had either attempted suicide or experienced suicidal ideation. A study conducted in the United States reported that $41 \%$ of transgender participants attempted suicide compared with $1.6 \%$ in the general population [15]. An Australian national study found that $57.2 \%$ of transgender people had been diagnosed with depression at some point in their lives, a rate 4 times higher than among the general population. It was reported that $39.9 \%$ of them had been diagnosed with anxiety, with around $50 \%$ higher than the background rate [16]. In this study, the low prevalence of mental disorders in comparison with studies in other countries might be related to the fact that these patients have visited a medical care provider only for gender dysphoria without sufficient evaluation of other general mental disorders, such as depression and anxiety. Therefore, it is important to evaluate patients for other mental health problems so that they can receive the appropriate psychological counseling and therapy. Moreover, multidisciplinary specialty teams as mentioned in the official guidelines should be organized including mental health professionals.

In this study, transgender patients were assessed for $\mathrm{HT}$ in accordance with the official guidelines and, if appropriate, the cross-sex hormone was administered. However, this therapy may have associated risks that should be taken into consideration. Increased risks of feminizing HT for MTFs include cardiovascular disease, especially venous thromboembolism (VTE), hypertriglyceridemia, and prolactinoma. We attempted to lower cardiovascular disease, especially VTE disease risk for smokers, by administering transdermal estrogen [17]. It has been reported that smoking may be associated with an increased risk of cardiovascular diseases [18]. Therefore, we emphasized the importance of smoking cessation for patients who visited our hospital. We also used transdermal estrogen for older patients who demonstrated an increased risk of cardiovascular disease. We routinely performed physical examinations to prevent and detect these side effects early, and adjusted the serum testosterone and estradiol concentrations to the normal physiologic range [1].

Moreover, in FTM patients, we performed past history tak- ing and comorbidity condition assessments prior to starting HT in accordance with the official guidelines. The baseline laboratory test was evaluated for indications of possible future adverse events. We routinely evaluated the physical examination and adjusted the serum testosterone to the normal physiologic range. Furthermore, we monitored the hemoglobin and lipid levels because of the erythropoietic and metabolic effect of testosterone. The Endocrine Society Clinical Practice Guideline review identified 29 eligible studies at moderate risk of bias. In the literature, cross-sex hormone in FTMs was associated with a statistically significant increase in serum TG and LDL-C levels. High-density lipoprotein cholesterol levels decreased significantly across all follow-up time periods [19].

To assess the bone health of transgender patients who were planning on receiving $\mathrm{HT}$, we measured $B M D$ in patients undergoing the baseline laboratory test. In this study, Z- and T-score for the BMD $\left(\mathrm{g} / \mathrm{cm}^{2}\right)$ test before or after HT were within the normal ranges. This may be related to the fact that the majority of these transgender people were in their 20 s or 30 s and were administered cross-sex hormones. In the present study, estrogen alone was capable of maintaining bone mass in MTFs. Conversely, testosterone administration maintained BMD in FTMs [20]. In another study, transgender persons who had undergone gonadectomy sometimes chose not to continue consistent cross-sex HT after hormonal and surgical sex reassignment, thereby becoming at risk for bone loss [19].

In transgender patients who underwent gender affirmation surgery, genital plastic surgery was more common in MTFs than in FTMs. This may be related to common postoperative complications of genital plastic surgery for FTMs, which are likely to affect a patient's satisfaction level. In a study that investigated 330 MTFs who underwent primary penile inversion vaginoplasty, 95 (28.7\%) patients sustained postoperative complication and $3(0.9 \%)$ developed recto-neovaginal fistulas. A total of 30 (9.0\%) patients required a second operation [21]. However, with respect to SRS for FTMs, most such surgeries are associated with a rate of urethral stricture as high as $51 \%$, which decreases only to $23-35 \%$ even among the most experienced contemporary surgeons [22]. As such, postoperative complications may be related to differences in the use of genital plastic surgery between MTFs and FTMs.

This study has several limitations. First, the sample size was 


\title{
Obstetrics \& Gynecology Science
}

\author{
Vol. 62, No. 1, 2019
}

too small to assess the general trend among transgender people. There were many missing data because of the retrospective nature of the study. Additionally, laboratory data were not enough to study the long-term effect of HT, and BMD was usually measured only once. Thus, it was impossible to investigate the change before and after medical transition. It was not sufficient to accurately evaluate transgender people's bone health either. Therefore, future researchers need to make continued efforts to examine the association between cross-sex $\mathrm{HT}$ and bone health by checking BMD and bone markers.

Finally, medical providers must reduce barriers to transgender people's medical management by fully understanding the physiology and medical knowledge of transgender health care. There should be continued proactive research on the physiological impact of HT, changes in hematological findings, bone turnover markers, and BMD.

\section{Conflict of interest}

No potential conflict of interest relevant to this article was reported.

\section{Ethical approval}

The study was approved by the Institutional Review Board of Soonchunhyang University Seoul Hospital (IRB No. 201804-002) and performed in accordance with the principles of the Declaration of Helsinki. Written informed consents were exempted.

\section{References}

1. Coleman E, Bockting W, Botzer $M$, Cohen-Kettenis $P$, DeCuypere G, Feldman J, et al. Standards of care for the health of transsexual, transgender, and gendernonconforming people, version 7. Int J Transgenderism 2012;13:165-232.

2. Winter S, Diamond M, Green J, Karasic D, Reed T, Whittle $S$, et al. Transgender people: health at the margins of society. Lancet 2016;388:390-400.

3. Reed GM, Drescher J, Krueger RB, Atalla E, Cochran SD,
First $\mathrm{MB}$, et al. Disorders related to sexuality and gender identity in the ICD-11: revising the ICD-10 classification based on current scientific evidence, best clinical practices, and human rights considerations. World Psychiatry 2016;15:205-21.

4. Bakker A, van Kesteren PJ, Gooren LJ, Bezemer PD. The prevalence of transsexualism in The Netherlands. Acta Psychiatr Scand 1993;87:237-8.

5. Tsoi WF. The prevalence of transsexualism in Singapore. Acta Psychiatr Scand 1988;78:501-4.

6. Van Caenegem E, Wierckx K, Elaut E, Buysse A, Dewaele $A$, Van Nieuwerburgh $F$, et al. Prevalence of gender nonconformity in Flanders, Belgium. Arch Sex Behav 2015;44:1281-7.

7. Glen F, Hurrell K. Technical note: measuring gender identity. Manchester: Equality and Human Rights Commission; 2012.

8. Herman JL, Flores AR, Brown TN, Wilson BD, Conron KJ. Age of individuals who identify as transgender in the United States. Los Angeles (CA): The Williams Institute, UCLA School of Law; 2017.

9. Kuyper L, Wijsen C. Gender identities and gender dysphoria in the Netherlands. Arch Sex Behav 2014;43:37785.

10. Clark TC, Lucassen MF, Bullen P, Denny SJ, Fleming TM, Robinson EM, et al. The health and well-being of transgender high school students: results from the New Zealand adolescent health survey (Youth'12). J Adolesc Health 2014;55:93-9.

11. Conron KJ, Scott G, Stowell GS, Landers SJ. Transgender health in Massachusetts: results from a household probability sample of adults. Am J Public Health 2012;102:118-22.

12. Lee H, Park J, Choi B, Yi H, Kim SS. Barriers to transitionrelated healthcare among Korean transgender adults: focused on gender identity disorder diagnosis, hormone therapy, and sex reassignment surgery. Epidemiol Health 2018;40:e2018005.

13. Price TM, Blauer KL, Hansen M, Stanczyk F, Lobo R, Bates GW. Single-dose pharmacokinetics of sublingual versus oral administration of micronized $17 \beta$-estradiol. Obstet Gynecol 1997;89:340-5.

14. Hong J, Lee D, Ham B, Lee S, Sung S, Yoon T, et al. The survey of mental disorders in Korea. Sejong: Ministry of Health \& Welfare; 2017 


\section{Obstetrics \& Gynecology Science}

Hyun Hye Lim, et al. Affirmative care of transgender people

15. Haas AP, Rodgers PL, Herman JL. Suicide attempts among transgender and gender non-conforming adults: findings of the national transgender discrimination survey. Los Angeles (CA): The Williams Institute; 2014.

16. Hyde Z, Doherty M, Tilley M, McCaul K, Rooney R, Jancey J. The first Australian national trans mental health study: summary of results. Perth: School of Public Health, Curtin University; 2013.

17. Toorians AW, Thomassen MC, Zweegman S, Magdeleyns EJ, Tans G, Gooren LJ, et al. Venous thrombosis and changes of hemostatic variables during cross-sex hormone treatment in transsexual people. J Clin Endocrinol Metab 2003;88:5723-9.

18. Lakier JB. Smoking and cardiovascular disease. Am J Med 1992;93:8S-12S.

19. Hembree WC, Cohen-Kettenis PT, Gooren L, Hannema $\mathrm{SE}$, Meyer WJ, Murad MH, et al. Endocrine treatment of gender-dysphoric/gender-incongruent persons: an endocrine society clinical practice guideline. J Clin Endocrinol Metab 2017;102:3869-903.

20. Spinder T, Spijkstra JJ, van den Tweel JG, Burger CW, van Kessel H, Hompes PG, et al. The effects of long term testosterone administration on pulsatile luteinizing hormone secretion and on ovarian histology in eugonadal female to male transsexual subjects. I Clin Endocrinol Metab 1989;69:151-7.

21. Lips P, Asscheman H, Uitewaal P, Netelenbos JC, Gooren $\mathrm{L}$. The effect of cross-gender hormonal treatment on bone metabolism in male-to-female transsexuals. J Bone Miner Res 1989;4:657-62.

22. Santucci RA. Urethral complications after transgender phalloplasty and strategies to treat them and minimize their occurrence. Clin Anat 2018:31:187-90. 